\title{
Descortinando Fahrenheit 9/11: as estratégias de Michael Moore
}

\author{
Laís Farago Vieira \& Vanessa Matos dos Santos*
}

Fahrenheit 9/11 (Estados Unidos, 2004, cor, 122 min.)

Direção: Michael Moore

Produção: Michael Moore, Jim Czarnecki, Kathleen Glynn

Coprodução: Kurt Engfehr, Jeff Gibbs

Produção executiva: Harvey Weinstein, Bob Weinstein, Agnès Mentre

Roteiro: Michael Moore

Narração: Michael Moore

Elenco: Michael Moore

Música : Jeff Gibbs

Edição: Kurt Engfehr, Todd Woody Richman, Chris Seward

Distribuição: Lions Gate Films, IFC Films

\section{Apresentação}

A presente crítica é resultado de uma pesquisa acerca dos acontecimentos de 11 de setembro de 2001 nos Estados Unidos, destacando especialmente o documentário Fahrenheit 9/11 (2004), de Michael Moore. Partindo do fato de que Moore utilizou a estrutura fílmica hollywoodiana para disseminar sua visão acerca dos acontecimentos relacionados àquele 11 de setembro de 2001, passa-se à desconstrução de Fahrenheit $9 / 11$ por meio da análise fílmica para descortinar as estratégias utilizadas pelo documentarista.

De acordo com Ramos e Serafim (2007), o método fílmico surgiu nos EUA em 1942, quando Gregory Bateson e Margaret Mead passaram a utilizar a fotografia e o cinema com a finalidade de observar e compreender os comportamentos de grupos étnicos de diferentes regiões. Para atingir os seus objetivos, os pesquisadores utilizavam documentários como Nanook e Moana, de

* Laís Farago Vieira: Jornalista. Universidade Federal de Uberlândia - UFU, Grupo de Estudos e Pesquisa em Tecnologias, Comunicação e Educação - UFU. 38408-100, Uberlândia, Minas Gerais, Brasil. E-mail: laisfarago@gmail.com

Vanessa Matos dos Santos: Universidade Federal de Uberlândia - UFU. Programa de Pós-Graduação em Tecnologias, Comunicação e Educação - PPGCE. 38408-100, Uberlândia, Minas Gerais, Brasil. E-mail: vanessamatos@ufu.br

Doc On-line, n. 23, março de 2018, www.doc.ubi.pt, pp. 196-211. 
Flaherty, que retratavam exatamente o que Bateson e Mead buscavam. Para Vanoye e Goliot-Lété (2005), os filmes documentários estão inseridos em um determinado contexto sociológico e histórico e, por isso, essas produções podem ser utilizadas para compreender uma sociedade. Porém, deve-se levar em conta que mesmo em um documentário onde o principal objetivo é retratar um fato real, na maioria das vezes, a sociedade não é mostrada tal como é, mas sim encenada, visto que documentários visam ressaltar um determinado ponto de vista. Considerando a análise fílmica como metodologia, Fahrenheit $9 / 11$ foi dividido em blocos temáticos com a finalidade de destacar trechos isolados que não são percebidos quando observados a partir da totalidade (Vanoye e GoliotLéTé, 2005). Ainda de acordo com os autores, o segundo passo é estabelecer elos entre elementos aparentemente isolados, a fim de dar um significado à produção cinematográfica. Para a descrição e interpretação do objeto a partir da análise fílmica, devem-se considerar elementos internos e externos ao documentário.

\section{Iniciando a desconstrução}

Desta forma, para efeito de análise, Fahrenheit $9 / 11$ foi dividido em nove blocos temáticos. Essa divisão se deu a partir da observação dos principais temas tratados por Moore e após correlacioná-los à estrutura fílmica hollywoodiana. Os documentários não tem nenhum tipo de compromisso em seguir tal estrutura que começou a ser desenvolvida por Syd Field (2005) com base no Paradigma do teatro Clássico, mas partimos do pressuposto de que o filme de Moore está estrategicamente estruturado desta maneira, como segue. TC IN e TC OUT indicam, respectivamente, o tempo inicial e o tempo final de cada bloco. 


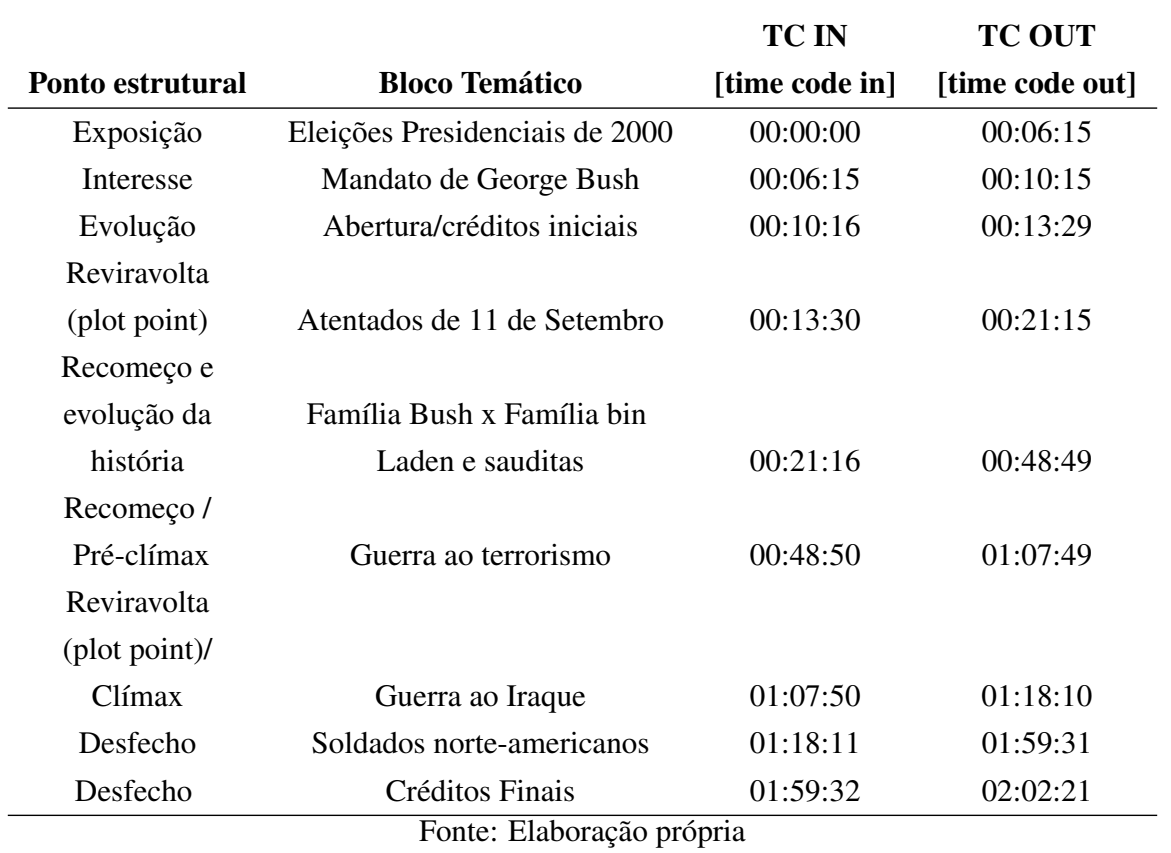

Escrito, dirigido e produzido pelo documentarista americano Michael Moore, Fahrenheit 9/11 (2004) é um documentário que trata sobre os acontecimentos de 11 de setembro de 2001 nos Estados Unidos, ressaltando suas causas e consequências. O principal objetivo de Moore através dessa produção é fazer uma dura crítica em relação ao governo de George Bush, tendo como motivação o 11 de setembro nos EUA. A partir daí, o diretor traz diversos desdobramentos, como o vínculo entre as famílias Bush e bin Laden, a invasão do Iraque, bem como o recrutamento de soldados norte-americanos.

Segundo Camelo et al. (2009), o título do documentário faz alusão ao livro Fahrenheit $451,{ }^{1}$ visto que Moore pretende deixar explícito a temperatura política dos EUA, que além de queimar papéis oficiais a fim de ocultá-los, também queimava pessoas. Considerando o que Penafria (1999) diz em relação aos temas nos documentários, Fahrenheit 9/11 traz uma questão polêmica, que utiliza aspectos do passado para explicar o presente. Nesse aspecto, a produção de um documentário que retrate as causas e consequências dos acontecimentos de 11 de setembro é importante, visto a sua repercussão "para além das fronteiras dos Estados Unidos" (Camelo et al., 2009). Moore reuniu histórias de diferentes pessoas a fim de revelar algo para a sociedade. Através da mon-

1. Fahrenheit $451\left(233^{\circ} \mathrm{C}\right)$ foi escrito por Ray Bradbury, em 1953. O título do livro representa a temperatura que queima o papel. Segundo Camelo et al. (2009: 07), a história "aborda o futuro e o controle da sociedade por um governo ou classe", retratando um cenário de opressão em uma sociedade pós-guerra. 
tagem do documentário, Moore conseguiu atingir o contexto desejado, visto que este é um documentário "de intencionalidades e, por que não, manipulações por parte do roteirista, que assume os vários papeis ao mesmo tempo: narrador, roteirista e personagem" (Camelo, et al., 2009: 02).

$\mathrm{O}$ estilo de Michael Moore se mostrou ainda mais forte em Fahrenheit 9/11, visto que o documentarista é bastante claro em relação à sua posição, afirmando diversas vezes que sua produção se trata de uma luta contra Bush. A fim de influenciar os eleitores contra Bush, Moore levou Fahrenheit 9/11 aos cinemas americanos em 25 de junho de 2004, cinco meses antes das eleições presidenciais e, por isso, segundo Camelo et al. (2009: 08), o documentário entrou "para a história da indústria cinematográfica como o documentário de maior arrecadação de bilheteria nos EUA". Além de faturar mais de três milhões de dólares nos três primeiros dias, o documentário ganhou diversos prêmios. Mas, vejamos como exatamente e, sobretudo, com quais estratégias, este filme foi produzido.

\section{Bloco temático 1: Eleições presidenciais de 2000}

Por ter sido produzido em 2004, Michael Moore inicia Fahrenheit 9/11 questionando se o que ocorreu quatro anos atrás foi um sonho ou realidade. Ele está se referindo, em primeiro plano, às eleições presidenciais americanas de 2000, disputada por Al Gore e George Bush. Mas, além disso, é possível ir além e levantar o questionamento num segundo plano: trata-se de uma ficção (portanto sonho) ou documentário (realidade)? A partir deste início, é possível que se visualize uma leitura (evidente e objetiva) em primeiro plano e uma leitura em segundo plano (nem sempre tão evidente). As características destas leituras serão desenvolvidas mais a frente.

Neste momento, Moore utiliza imagens da maioria dos telejornais anunciando a vitória de $\mathrm{Al}$ Gore em muitos estados americanos. Em seguida, aparecem imagens do canal Fox News apresentando Bush como candidato eleito. Depois disso, todos os outros canais de TV voltam atrás e pedem desculpas por terem apresentado Al Gore como vencedor das eleições. Apesar de conseguirem provar que Gore liderava todas as pesquisas de preferência de voto, Bush conseguiu destaque nas manchetes, pois o seu primo trabalhava na Fox News, que por sinal possuía maior credibilidade, sendo capaz de influenciar as informações transmitidas pelas outras redes de TV do país. A partir daí, Moore sugere que as eleições presidenciais tenham sido fraudadas em virtude das influências exercidas por Bush. 


\section{Bloco temático 2: Mandato de George Bush}

Nos primeiros oito meses de mandato, Bush enfrentou diversas dificuldades e o seu índice de aprovação caiu consideravelmente, sendo considerado um presidente sem futuro. Por isso, nesse bloco, Moore exibe uma série de imagens que retratam as tomadas de decisões dos republicanos, vistas como desastrosas, e que, e um futuro bem próximo, afetariam o país. Nesse momento, "uma música melancólica, parecida com o som de violão, entre imagens que constroem os principais membros dos grupos dos "privilegiados", imprime o sentido de que dias piores estariam por vir" (Victorino, 2014: 281).

Em resposta às dificuldades enfrentadas em seu governo, Bush decidiu tirar férias. A partir dessa asserção, Moore ilustra as férias do presidente a partir de imagens de arquivo pessoal e sempre fazendo críticas à maneira de Bush governar. Até esse ponto do documentário, Moore traz todo um contexto histórico de como se deu a conturbada eleição de Bush e seus primeiros meses de mandato, para auxiliar que o espectador compreenda em que momento ocorreram os acontecimentos de 11 de setembro. Moore deixa claro que George Bush voltou ao trabalho em 10 de setembro de 2001 e que ao final do seu dia de trabalho, o presidente dormiu confortavelmente: "naquela noite ele dormiu em lençóis de linho francês" (Fahrenheit 9/11, 2004). Nesse momento do filme, Moore deixa subentendido que provavelmente aquela foi a última boa noite de sono do presidente antes do 11 de setembro.

\section{Bloco temático 3: Abertura/créditos iniciais}

A abertura do filme começa com pouco mais de dez minutos corridos. Juntamente aos créditos de produção de Fahrenheit 9/11, aparecem os principais políticos envolvidos com Bush. Abertura que mostra os bastidores, como se o filme pudesse exibir aquilo que as emissoras de TV não mostraram. Essa abertura mostra, inclusive, testes de som e ajustes de áudio. Risos e ensaios. Esses membros são mostrados atrás das câmeras, se preparando para discursar em rede nacional. Victorino (2014) afirma que as imagens das principais figuras políticas durante o governo de Bush é importante para que Moore aproxime o público, de modo geral, do contexto do documentário, pois essas pessoas são conhecidas principalmente pelo espectador americano. Sem essas imagens logo na abertura, ficaria difícil para que públicos de outros países identificassem quem são aquelas figuras consideradas importantes na política dos EUA.

Essa parte é na, verdade, a abertura do material. Passados mais de 13 minutos de filme, finalmente é possível identificar - em tela - o escritor, produtor e diretor da obra. Essa informação aparece em letras brancas sobre um fundo 
preto e adquire a mesma importância de uma vinheta na produção televisiva: ela marca o início, fim ou pausa em uma exibição. Essa estratégia é bastante utilizada pela televisão comercial aberta no Brasil: ao final de um programa, logo inicia-se outro em fluxo contínuo. A vinheta de abertura (e intervalo comercial) só vai surgir após cerca de 10 minutos de exibição do material - tempo suficiente para que o telespectador já se veja engajado na nova emissão e decida se quer ou não acompanhá-la. No caso do filme de Moore, fica muito difícil que o telespectador resista, pois a narrativa passa a exibir características do momento de evolução das produções hollywoodianas. Esse é o momento em que as histórias começam a fazer sentido para o telespectador e as peças começam a se juntar para formar um mosaico maior de significações e sentidos.

\section{Bloco temático 4: Acontecimentos de 11 de setembro de 2001}

Para abordar os acontecimentos de 11 de setembro, o Moore utiliza uma tela negra e vozes de pessoas gritando, juntamente ao som dos aviões se chocando contra os prédios do World Trade Center. Segundo Victorino (2014), ao utilizar o artifício da cor preta ao fundo, Moore faz com que o espectador reconstrua as imagens dos acontecimentos na própria mente, a fim de inserilo naquele dia. Após um minuto utilizando esse recurso, Moore traz imagens do local, buscando ressaltar as reações dos americanos em relação ao choque dos aviões com as torres. No momento dos acontecimentos que marcariam os símbolos financeiros e militares do país, Bush se dirigia para uma escola na Flórida. Ao saber sobre o primeiro avião que atingiu o WTC, o presidente decidiu seguir com a sua visita na escola, considerada por Moore como uma grande manobra publicitária. Após saber que outros símbolos do país estavam sendo atingidos, Bush continuou a ler para as crianças por cerca de sete minutos.

Para Moore (2004: 33), "o senhor Bush decidiu seguir em frente com a programação montada para render boas fotos". Kean et al. (2004), por seu turno, afirma que o presidente queria aparentar calma, pois a imprensa estava presente e Bush queria entender melhor o que estava acontecendo no país, ao invés de deixar transparecer todo o nervosismo que envolvia aquele momento de crise. Aos 18 minutos e 17 segundos, Moore, em voz over, faz diversas sugestões acerca do que se passava na cabeça de Bush ao receber a notícia dos atentados. O documentarista questiona se naquele momento, o presidente estava refletindo se deveria ter lido o relatório que recebeu em 06 de agosto daquele mesmo ano, dizendo que Osama bin Laden planejava atacar os EUA. Neste momento, Moore satiriza Bush ao sugerir que o título do relatório era vago demais. A partir deste ponto, cria-se justamente o questionamento óbvio: 
por quais razões nada foi feito? A resposta para esta questão permite que se visualize o primeiro ponto de virada proposto na estrutura de Syd Field (2005).

\section{Bloco temático 5: Família Bush x Família bin Laden e sauditas}

Nos dias seguintes aos acontecimentos de 11 de setembro, o governo ordenou que o espaço aéreo do país fosse fechado, a fim de evitar quaisquer ataques que pudessem vir do céu. Porém havia aviões disponibilizados pelo governo para retirar a família bin Laden e outros sauditas do território americano. Moore prossegue o documentário utilizando o recurso do depoimento, com asserções imagem-câmera de Jack Cloonan, investigador aposentado do FBI, que afirmava que a retirada dos familiares de bin Laden do país foi um erro, comprometendo diversas investigações acerca da Al-Qaeda. A fim de comprovar as asserções acerca desse trecho, Moore utiliza entrevistas com especialistas e pesquisadores.

Neste caso específico, as entrevistas são conduzidas de forma bastante indutiva Trata-se de uma estratégia telejornalística que, muitas vezes, realiza junção de trechos distintos de entrevista para compor uma informação final mais completa. Neste caso, o que ocorre é um processo de edição e não de montagem - que seria mais adequado a um documentário. Um documentário que se propõe a mostrar uma outra face do 11 de setembro não deveria estar preocupado com a questão do tempo (que é geralmente o caso do telejornalismo). Mas, entende-se, claramente, que esta estratégia permite dar mais agilidade às imagens e às informações oferecidas pelos entrevistados. Aqui a estratégia visa mostrar a "verdade"a partir de vários ângulos.

Nesse bloco do documentário, Moore também aborda a relação da família Bush com a família de bin Laden: anos antes do 11 de setembro nos EUA, James Bath, amigo de Bush, foi contratado pelos bin Laden para administrar seus negócios no Texas. Nessa época, Bush trabalhava em uma empresa multinacional que investia em indústrias controladas pelo governo, principalmente na área de defesa - a Carlyle Group - uma das empresas que tinha os bin Laden como investidores. Em outras palavras, quando os EUA gastava com defesa, os bin Laden lucravam, pois a Carlyle era uma das principais fornecedoras de itens de defesa do governo americano. A partir dessas relações estabelecidas por Moore, conclui-se que os bin Laden lucraram com o 11 de setembro, pois no ano dos acontecimentos, os EUA, mais do que nunca, investiu em armamentos e outros itens de defesa, como tanques de guerra fabricados pela Carlyle. Vale ressaltar que na época do 11 de setembro, o pai de Bush e ex-presidente dos EUA era consultor da multinacional no continente asiático, mantendo contato com a família bin Laden. Acerca dessa temática, aos 34 minutos e 20 
segundos, Moore traz à tona alguns questionamentos que inquietavam os americanos: sendo os sauditas os maiores provedores da família Bush, dando a eles mais lucro que os cargos de presidência, a quem os Bush favoreceriam? Os americanos ou os sauditas? Está posto, a partir deste momento, o elemento emblemático da narrativa: a evolução da história que deve culminar no préclímax.

\section{Bloco temático 6: Guerra ao terrorismo}

Utilizando manchetes de diversos telejornais, Moore inicia esse bloco temático ilustrando que, em dezembro de 2001, as grandes redes de TV receberam informações do governo federal que os EUA estava sob ataque, e que dessa vez, poderia ser pior que os atentados de 11 de setembro. Através dessa atitude, o governo de Bush visava instaurar uma aura de ameaça, manipulando os cidadãos americanos. Aos 50 minutos e 05 segundos, Moore traz imagens de discursos de Bush, dizendo que nenhum americano estava seguro, pois "o mundo mudou depois de 11 de setembro" (Fahrenheit, 2004).

O sentimento de medo criado pelo governo americano foi tão grande que, através de depoimentos, mesmo moradores de cidades pequenas e com baixo potencial para um ataque terrorista contam que não conseguiam dormir tranquilos e pediam proteção para seus líderes governamentais. Para ilustrar a preocupação da população americana em relação aos possíveis ataques terroristas, Moore toma depoimentos de um grupo pacifista (Peace Fresno) da pequena cidade de Fresno, na Califórnia, que se reunia semanalmente para discutir questões relativas à paz. Segundo a Peace Fresno, Aaron Kilner, membro da equipe de antiterrorismo da cidade, se infiltrou no grupo para investigar possíveis ações terroristas que seus membros poderiam planejar. Aos 59 minutos e 21 segundos, utilizando imagens que ilustram as reuniões do grupo, Moore, através de argumentos irônicos, deixa subentendido que a Peace Fresno está bem longe de ser uma organização terrorista, pois são apenas cidadãos em busca de discussões positivas.

\section{Bloco temático 7: Guerra ao Iraque}

Neste bloco temático, Moore trabalha com a guerra dos Estados Unidos contra o Iraque. Para fazer referência aos conflitos que abordará a seguir, Moore utiliza imagens (1h07min50s) de bombas em navios de guerra. Em seguida, Moore intercala as imagens dos navios de guerra a imagens de Bush se preparando para um discurso em rede nacional, no dia 19 de março de 2003. Moore utiliza o discurso do presidente em off, e, a fim de ilustrá-lo, intercala 
imagens de tropas preparando mísseis e bombas com imagens de Bagdá, capital do Iraque. Enquanto Bush fala acerca de um povo oprimido, cujo líder - Saddam Hussein - ameaça o mundo com destruição em massa e propagação do terrorismo, as imagens mostram uma criança brincando em um parque de Bagdá, e de repente, um corte mostra a explosão de uma bomba impactante (01h09min21s), fazendo referência à primeira noite de ataques na cidade. Enquanto isso, em voz over, Moore afirma que o Iraque nunca cogitou a possibilidade de atacar os EUA e que, aquele país não deveria ter sido bombardeado. Em seguida, o documentarista mostra uma criança pequena morta, sendo colocada em uma caminhonete que passava recolhendo os cadáveres de vítimas da guerra.

É interessante notar como Moore consegue depoimentos dos próprios soldados americanos a seu favor: um soldado afirma que ele e seus colegas não foram preparados pra guerra e, chegando ao Iraque, por medo, eles atiravam em tudo que se movesse, o que causou a morte de muitos inocentes. Contrapondo esse fato e, querendo ressaltar o nacionalismo exacerbado americano através do discurso de ódio contra os supostos inimigos dos EUA, Moore também mostra soldados americanos com orgulho do trabalho que estavam fazendo naquele país. Para justificar a guerra no Iraque, Bush não mede esforços e passa um bom tempo tentando convencer a opinião pública a seu favor. Este bloco no entanto, não termina, sem que Moore busque, por meio da montagem do material, lançar mão da espetacularização - elemento típico das produções hollywoodianas. Em 1h13 do filme, representantes do governo de Bush explicam como os alvos foram escolhidos e destacam a importância de serem humanos. Paralelamente, suas falas são cobertas por imagens de crianças feridas, mulheres pedindo socorro e a mais emblemática: ao fundo completamente destruído, uma senhora grita, chora e desespera. Não é possível entender nenhuma palavra do que ela diz, mas aqui vale a linguagem das emoções, acessíveis a qualquer pessoa. Em seguida, por meio de uma leitura mais evidente, Moore busca mostrar o poder de persuasão do presidente americano. Moore exibe uma entrevista da cantora pop Britney Spears, declarando seu apoio e confiança em todas as decisões do governo. Numa leitura mais profunda, o que Moore faz é evidenciar a alienação do povo por meio do uso da imagem da cantora pop. Prova disso é o fato que de a narração do filme segue afirmando que "Britney Spears não estava sozinha", posto que muitos acreditavam em Bush.

Finalizando esse bloco, o documentarista aponta uma contradição nas falas do presidente Bush e seu governo: no início do mandato, em 2001, Bush declarava que o Iraque não possuía poder bélico que gerasse grande preocupação. Após os ataques de 11 de setembro, o discurso mudou e o presidente 
afirmava com convicção que o país liderado por Saddam possuía armas químicas e apoiava a Al-Qaeda.

\section{Bloco temático 8: Soldados norte-americanos}

Moore inicia esse bloco fazendo uma dura crítica à cobertura da imprensa norte-americana no período da Guerra no Iraque. Para o documentarista, a imprensa dos EUA era tendenciosa e manipulada pelo governo, que por sua vez, não permitia a divulgação de dados oficiais sobre soldados mortos. O documentário mostra também, de que modo o exército americano recrutava soldados para lutarem na guerra no Iraque. Para Moore, o governo procurava em locais onde a economia estava arruinada, cuja única chance de emprego era servir ao exército. $\mathrm{O}$ documentarista cita como exemplo sua cidade natal, Flint (no Michigan), onde cerca de 50\% da população estava desempregada. A partir daí, Moore constrói a história de Lila Lipscomb, mãe do sargento Michael Pedersen, morto no Iraque.

Nesse bloco temático, Moore também busca retratar a dificuldade de reabilitação dos soldados mutilados e critica o governo, que fez grandes cortes orçamentários em relação às ajudas de custo aos veteranos de guerra e suas famílias.

Os minutos finais do documentário se passam na frente do Capitólio, onde Moore questiona os congressistas sobre mandar seus filhos para a guerra no Iraque. Segundo Moore, apenas um congressista, dos 535, tinha seu filho servindo ao país na guerra. Para o documentarista, as pessoas pobres e que vivem em dificuldade se alistam para defender um sistema que os prejudica. Essas pessoas se alistam para que outros (como os filhos de políticos ou pessoas de classes mais favorecidas) não tenham que se alistar. "Elas desistem de suas vidas para que sejamos livres" (Fahrenheit, 2004). Moore encerra o documentário com uma fala de George Bush, dizendo "se me enganar... não me enganará outra vez" (Fahrenheit, 2004). Moore, em voz over, diz concordar com o presidente pela primeira vez. O documentarista, ao encerrar a produção com essa fala juntamente à imagem de Bush congelada faz menção às eleições de 2000, onde Bush pode até tê-lo enganado juntamente a toda a população americana, porém não o fará novamente, pois através do exibido no documentário, Moore esperava prejudicar a reeleição do presidente.

\section{Bloco temático 9: Créditos Finais}

Nos créditos finais, Moore dedica o documentário a Michael Pedersen e todos os soldados de Flint que perderam a vida na guerra no Iraque. A seu 
amigo Bill Weems e as 2973 vítimas dos atentados de 11 de setembro de 2001 e, principalmente, aos que perderam a vida no Iraque e Afeganistão devido às atitudes do governo americano. Em 1h59min55s a dedicatória é cortada e a tela é destinada aos créditos de produção do documentário, ainda com a música de Neil Young ao fundo: são nomeados todos aqueles que participaram da produção, pesquisa, processo de filmagem e edição de Fahrenheit 9/11. Nos últimos segundos, Moore indica o seu website (www.michaelmoore.com), com a frase "do something" na legenda, um pedido para que as pessoas façam algo em relação à política americana, visto que o site é um espaço para que as pessoas se mobilizem acerca dos temas tratados em seus filmes.

\section{Considerações finais}

Em Fahrenheit 9/11, Michael Moore visa, além de criticar o governo Bush, romper com o "estilo de vida americano" ou o tão almejado "American Dream" exercendo uma forte crítica à sociedade americana como um todo. A crítica de Moore à imprensa norte-americana aparece logo nos primeiros minutos do documentário, a fim de problematizar a cobertura da eleição de Bush como presidente dos EUA. Nesse sentido, é importante discutir de que forma Moore impõe sua crítica, mas, sobretudo, entender do que efetivamente o documentarista fala.

Produzido como uma obra de ficção, Fahrenheit 9/11 utiliza a estrutura tripartite que, invariavelmente, prende os olhos e a atenção de um público que já está condicionado por filmes desta natureza. Embora esta seja a estrutura utilizada, o tema em si e a forma de abordá-lo é, em essência, documental. Trata-se, sem dúvida, de um documentário, mas, destaque-se, que lança mão de diversas estratégias na construção da narrativa. A primeira delas é a estruturação estilo filme de ficção hollywoodiana. Essa estratégia permite que a atenção do telespectador seja renovada a cada plot point (ou reviravolta). Ao longo das duas horas de documentário fica claro que, para tratar de uma história recente e que fez parte da vida da população norte-americana, Moore traz diversos recursos visuais provenientes da indústria ficcional hollywoodiana, como a abertura do seriado Bonanza, elemento parte da cultura norte-americana. Utilizando diversos recursos visuais e sonoros, Fahrenheit $9 / 11$ completa os espaços de ausência deixados pelo jornalismo (expressão da grande mídia) e o faz de forma a valorizar $\mathrm{o}$ aspecto documental da narrativa.

One of the markers of real, genuine authenticity in audio-visual media generally is a reduction often in the plenitude of images ... This applies to both 'real' reality coverage and the fabricated version found in some fictions. Absences or reduced quality of images - such as shaky camerawork, dodgy focus 
or awkward zooms - signify that events have not been staged for the convenience of the production of images. Coverage reacts to the events, rather than the events being created for, or through, the images themselves. In the case of September the 11 th, there were numerous such signifiers of actuality. (King, 2005: 50).

Através da montagem e de diferentes recursos utilizados para conferir verdade às suas asserções, o documentarista Michael Moore conseguiu criar um mosaico de significações e interpretações até mesmo para aquele público que não conhece a fundo a história dos Estados Unidos. Porém, é importante se atentar ao fato de que o documentarista muito critica a manipulação do governo Bush no que se refere aos meios de comunicação, mas também ele (Moore) faz o mesmo com os espectadores ao construir um documentário repleto de montagens e argumentos persuasivos. Desta forma, fica claro que Moore é um documentarista na medida em que produz um documentário mas também é, igualmente, um documentarista pois a construção se dá com o uso de estratégias fílmicas.

Para destacar o aspecto verídico de sua abordagem, Moore realiza entrevistas como se fossem para reportagens jornalísticas. Em diversos momentos, é possível observar que o entrevistador (Moore) induz a resposta. A edição em ritmo mais dinâmico também está mais voltada para reportagens televisivas que para montagens documentais, que permitem longas tomadas e trechos longos de entrevista.

É interessante ainda notar que, do ponto de vista dos regimes de leitura, o material se destaca pela leitura documentarizante mas não é ela que aparece no primeiro plano. Ao contrário disso, no primeiro plano surge a leitura fictivizante (regada pelas ironias do narrador, jogo de cena, edições satíricas etc). É como se Moore voltasse ao início de seu material em que lança a pergunta: sonho ou realidade? Não há dúvidas de que se trata de uma realidade (ainda que seja a realidade montada por ele), mas o documentarista oferece ao telespectador / leitor de sua obra a opção de escolher a forma como vai desenvolver tal leitura. Cabe ao telespectador / leitor decidir em qual das leituras ele vai se focar, mas nas duas o fim é o mesmo: a inabilidade e incompetência de Bush. É este o enredo de Fahrenheit 9/11 e não outro. O 11 de setembro é apenas um plot na narrativa toda. Em essência, o material trava uma batalha contra Bush. Não por acaso os primeiros minutos de filme são focados na eleição do então presidente. A todo momento, Moore desvela algum aspecto que corrobora a inabilidade presidencial e até o mau caratismo de Bush.

A mídia norte-americana também não saiu ilesa das críticas de Moore. Para ele, a imprensa se tornou a maior marqueteira da guerra, pois focou apenas nos pontos favoráveis, não retratando as suas consequências. Ao exibir 
imagens da cobertura da guerra no Iraque, Moore mostra a cena de um tanque de guerra e um jornalista, ao fundo, diz que as redes de TV estão fazendo história ao transmitirem a guerra para o mundo. Essa fala é a comprovação do que dizem Moreira (2004) e Wainberg (2005): a guerra, principalmente por ter a violência como um de seus ingredientes principais, desperta a curiosidade do público, estimulando o jornalista a transformá-la em um acontecimento midiático. Nesse aspecto, também é válido relacionar a cobertura da guerra do Iraque à ideia de sensacionalismo, visto que os meios de comunicação norteamericanos não se preocuparam em difundir o que de fato ocorreu, mas sim criar um espetáculo em torno da guerra, construindo o inimigo, a fim de atingir o patriotismo dos espectadores norte-americanos e influenciá-los a favor da guerra.

Fahrenheit 9/11 é um documentário com conteúdo denso e que certamente despendeu muita pesquisa. Mesmo que o documentarista não tenha atingido o seu principal objetivo (prejudicar a reeleição de Bush), ele conseguiu instaurar o sentimento de dúvida nos espectadores, fazendo pelo menos, com que esses questionassem o governo de Bush e também o próprio modo de vida norteamericano.

\section{Referências bibliográficas}

Alvares, C. (2005). O 11 de Setembro como mega-acontecimento: um desafio à globalização. Disponível em: http://revistas.ulusofona.pt/index.php /caleidoscopio /article/view/2242/1759

Aumont, J. \& Marie, M. (2006). Dicionário teórico e crítico de cinema. São Paulo: Papirus.

Aumont, J. et al. (1983). Esthétique du film. [S. 1.]: Nathan Université.

Araújo, I. (1995). Cinema: o mundo em movimento. São Paulo: Scipione.

Bauer, M. W. \& Gaskel, G. (org.) (2002). Pesquisa qualitativa com texto, imagem e som. Petrópolis: Vozes.

Brotas, A. (2005). Guerra e terrorismo: os diferentes discursos e enquadramentos da mídia. XXVIII Congresso Brasileiro De Ciências Da Comunicação (pp. 1-12). Rio de Janeiro. Anais. Salvador: FJA. Disponível em: www.intercom.org.br/papers/nacionais/2005/resumos/R0062-2.pdf

Camelo, A. P. et al. (2009). Uma sociedade estupefata perante o terror: a sociedade norte americana e os atentados de 11 de setembro na visão de Michael Moore. Contemporâneos: Revista de Artes e Humanidades, abr., (3): 1-32. Viçosa. Disponível em: www.revistacontemporaneos.com.br/n 3/pdf/fahrenheit.pdf 
Chermak, S. et al. (2003). Media representations of September 11. Westport, Conn.: Praeger.

Chomsky, N. (2005). Poder e terrorismo: entrevistas e conferências pós-11 de setembro. Rio de Janeiro: Record.

Chomsky, N. (2002). 11 de setembro. Rio de Janeiro: Bertrand Brasil, $6^{a}$ ed.

Comolli, J. L. (2008). Ver e poder. Belo Horizonte: Editora UFMG.

Field, S. (2005). Screenplay: the foundations of screenwriting. NY: Delta.

Gomes, S. (2013). P'ra lá do olho mecânico: de Vertov e Flaherty a Jean Rouch. Disponível em: www.academia.edu/9812247/P_RA_LÁ_DO_O LHO_MECÂNICO_De_Vertov_e_Flaherty_a_Jean_Rouch_2013_

Kean, T. H. et al. (2004). The 9/11 Commission Report. Eua: National Commission On Terrorist Attacks Upon The United States. Disponível em: http://govinfo.library.unt.edu/911/report/911Report.pdf

King, G. (2005). The spectacle of the real: from Hollywood to 'reality' TV and beyond. Intellect.

Maria, C. T. (2008). Um retrato da América pós-11 de setembro no cinema. Disponível em: www.unioeste.br/prppg/mestrados/letras/revistas/travessi as/ed_002/arte comunicacao/umretratonaamerica.pdf

Mombelli, N. F. \& Tomain, C. S. (2014). Análise fílmica de documentários: apontamentos metodológicos. Disponível em: http://lumina.ufjf.emnuve ns.com.br/lumina/article/ view/323/358

Moore, M. (2004). O livro oficial do filme Fahrenheit 11 de setembro. São Paulo: Francis.

Morais, T. (2008). "Nanook, O Esquimó”: discurso documental em consonância com as estratégias ficcionais. XXXI Congresso Brasileiro De Ciências Da Comunicação (pp. 1-15), Natal. Anais. Olinda: AESO. Disponível em: http://www.intercom.org.br/papers/nacionais/2008/resumos/R30777-1.pdf

Moreira, D. J. (2004). 11 de setembro de 2001: Construção de uma catástrofe nas primeiras páginas de jornais impressos. Dissertação de Mestrado em Comunicação e Semiótica, Pontifícia Universidade Católica de São Paulo, São Paulo. Disponível em: www.bocc.ubi.pt/pag/moreiradeodoro-11-setembro.pdf

Nichols, B. (2008). Introdução ao documentário. São Paulo: Papirus, 3. ed.

Odin, R. (2012). Filme documentário, leitura documentarizante. Significação: Revista de Cultura Audiovisual, 37 (39): 10-30. São Paulo. 
Online, Folha. (2001). Número de mortos nos ataques de 11 de setembro é de 3.278. Disponível em: www1.folha.uol.com.br/folha/reuters/ult112u939 6. shtml

Penafria, M. (2004). O filme documentário em debate: John Grierson e o movimento documentarista britânico. BOCC - Biblioteca online de Ciências da Comunicação. Disponível em: www.bocc.ubi.pt/pag/penafriamanuela-filme-documentario-debate.html

Penafria, M. (2003). O documentarismo do cinema. BOCC-Biblioteca online de Ciências da Comunicação. Disponível em: www.bocc.ubi.pt/pag/pena fria_manuela_documentarismo_cinema.pdf

Penafria, M. (1999). O filme documentário: história, identidade, tecnologia. Lisboa: Cosmos.

Pereira, A. S. M. (2005). O 11 de setembro na imprensa portuguesa: a semana seguinte. BOCC - Biblioteca online de Ciências da Comunicação. Dissertação de Mestrado em Comunicação e Jornalismo, Universidade de Coimbra, Coimbra. Disponível em: http://www.bocc.ubi.pt/pag/pereiraandreia-11-setembro-imprensa-portuguesa.pdf

Ramos, F. P. (2013). Mas afinal... o que é mesmo documentário?. São Paulo: Senac.

Ramos, F. P. (2001). O que é documentário?. BOCC - Biblioteca online de Ciências da Comunicação. Disponível em: www.bocc.ubi.pt/pag/pessoafernao-ramos-o-que-documentario.pdf

Ramos, N. \& Serafim, J. F. (2007). Cinema documentário, pesquisa e método: desafios para os estudos interdisciplinares. Disponível em: www.uff.br/c ontracampo/index.php/revista/article/view/358/161

Silverman, D. (2009). Interpretação de dados qualitativos: métodos para análise de entrevistas, textos e interações. Porto Alegre: Artmed.

Souza, B. M. (2012). A construção do conceito de inimigo nos discursos de Osama Bin Laden no período de 1996 a 2004. Dissertação (Mestrado em Relações Internacionais), Universidade Federal do Rio Grande do Sul, Porto Alegre. Disponível em: www.lume.ufrgs.br/bitstream/handle/1018 3/54091/000851264.pdf? sequence $=1$

Strawson, J. (2008) Islam and the politics of terrorism: aspects of the british experience. In M. Gani \& P. Mathew, Fresh perspectives on the war on terror. The Australian National University (ANU). Canberra / Australia.

Suppia, A. (2013). Quando a realidade parece ficção, é hora de fazer mockumentary. Ciência e Cultura, jan, 65 (1): 60-63. São Paulo. 
Triviños, A. N. S. (1987). Introdução à pesquisa em ciências sociais: a pesquisa qualitativa em educação. São Paulo: Atlas.

Vanoye, F. \& Goliot-Lété, A. (2005). Ensaio sobre a análise fílmica. Campinas: Papirus. $3^{\mathrm{a}}$ ed.

Victorino, L. (2014). O documentário vai à Hollywood: a paixão pelo "real"e os filmes de Michael Moore. Tese de Doutorado em Sociologia, Universidade de São Paulo, São Paulo. Disponível em: www.teses.usp.br/teses/di sponiveis/8/8132/tde-05112014-190949/en.php

Wainberg, J. A. (2005). Mídia e terror: comunicação e violência política. São Paulo: Paulus.

\section{Filmografia}

Fahrenheit 9/11 (2004), de Michael Moore. 